\title{
Juventude e educação: a música como influência no desenvolvimento escolar e a utilização de fones de ouvido entre os jovens de 15 e 17 anos
}

\begin{abstract}
Resumo:
Nesta pesquisa a partir de uma revisão bibliográfica e de coleta de dados em campo, buscou-se: estudar a função social da música e a influência que essa tem na vida dos jovens; conhecer e analisar quais os gêneros e estilos musicais que esses indivíduos escutam; identificar os motivos que os levam ao uso de fones de ouvido; $e$, descobrir se o uso constante dos mesmos podem ser uma distração e atrapalhar o seu desenvolvimento escolar. Para alcançar esses objetivos, dois procedimentos foram utilizados: estudo bibliográfico e questionário específico, de caráter quantitativo, com perguntas semiabertas destinado a estudantes de 15 a 17 anos. Os resultados obtidos, por meio dos referenciais teóricos, indicam que o jovem tem a necessidade de criar uma imagem para apresentar-se aos outros e a música está intimamente ligada a esse processo de expressão, liberdade e aceitação em um determinado grupo. Essas informações são consolidadas na análise de dados, pois o público alvo em questão afirma ouvir determinados gêneros e estilos musicais para não se sentirem excluídos. Com isso, percebemos que a música está incluída no conjunto de códigos que caracterizam os círculos de amizade dessa faixa etária.
\end{abstract}

\section{Palavras-chave: \\ Juventude. Educação Musical. Fones de ouvido.}

\section{Youth and education: music as an influence on school development and the use of headphones among 15 and 17 year olds}

Abstract: In this research, from a bibliographic review and data collection in the field, we sought to: Study the social function of music and the influence it has on the lives of young people; To know and analyze which genres and musical styles these individuals listen to; Identify the reasons that lead them to use headphones; And, find out if their constant use can be distracting and hinder your school development. To achieve these objectives, two procedures were used: a bibliographic study and a specific questionnaire, of a quantitative nature, with semi-open questions for students aged 15 to 17 years. The results obtained, through theoretical references, indicate that young people have the need to create an

1 Especialista em Metodologia do Ensino de Artes, Professora de Música na RME de Colombo e como professora de Arte na RME de Curitiba. E-mail: dani.martinezcoelho@gmail.com. ORCID iD: http://orcid.org/0000-0001-6447-2152. 
image to present themselves to others and music is closely linked to this process of expression, freedom and acceptance in a certain group. This information is consolidated in the data analysis, as the target audience in question claims to hear certain genres and musical styles in order not to feel excluded. With that, we realized that music is included in the set of codes that characterize the friendship circles of this age group.

Keywords: Youth. Musical education. Headphones.

\section{Juventud y educación: la música como influencia en el desarrollo escolar y el uso de auriculares entre los jóvenes de 15 y 17 años}

Resumen: En esta investigación, a partir de una revisión bibliográfica y recolección de datos en el campo, se buscó: Estudiar la función social de la música y la influencia que tiene en la vida de los jóvenes; Conocer y analizar qué géneros y estilos musicales escuchan estos individuos; Identificar las razones que les Ilevan a utilizar auriculares; Y averigüe si su uso constante pueden distraer y obstaculizar el desarrollo de su escuela. Para lograr estos objetivos se utilizaron dos procedimientos: un estudio bibliográfico y un cuestionario específico, de carácter cuantitativo, con preguntas semiabiertas para alumnos de 15 a 17 años. Los resultados obtenidos, a través de referencias teóricas, indican que los jóvenes tienen la necesidad de crear una imagen para presentarse a los demás y la música está íntimamente ligada a este proceso de expresión, libertad y aceptación en un determinado grupo. Esta información se consolida en el análisis de datos, ya que el público objetivo en cuestión afirma escuchar ciertos géneros y estilos musicales para no sentirse excluido. Con eso, nos dimos cuenta de que la música está incluida en el conjunto de códigos que caracterizan los círculos de amistad de este grupo de edad.

Palabras clave: Juventud. Educación musical. Audífonos.

\section{Introdução}

Esta pesquisa apresenta algumas considerações sobre juventude, educação, música e socialização, tendo como campo de estudo, jovens com idade entre 15 e 17 anos. Deste modo, a viabilidade deste trabalho está na sua contribuição para os estudos sobre a influência da música no desenvolvimento escolar e sua função socializadora e, por caracterizar-se não só como uma pesquisa bibliográfica, mas também de campo. GIL (1999, p. 71) considera que: “À medida que as próprias pessoas informam acerca de seu comportamento, crenças e opiniões, a investigação torna-se mais livre de interpretações calcadas no subjetivismo dos pesquisadores”. Assim, dentre as vantagens deste método, estão: a rapidez, a economia e a quantificação.

Algumas questões fazem parte dessa pesquisa: A música ajuda na socialização dos jovens? Como a música pode influenciar na vida social e educacional de estudantes entre 15 e 17 anos? De que maneira o uso de fones de ouvido pode influenciar neste processo?

Entre as fontes bibliográficas, utilizaram-se as contribuições de diversos autores, como: Franceschi (1984), Passerini (1996), Hummes (2004), Souza (2004), Santos (2006), Arroyo (2007), Grinspun (2007), Zampronha (2007), Fonterrada (2008), Aquino (2009), Pereira (2010), Zagonel (2012), Souza e Paiva (2012) etc.

Portanto, este artigo está divido em duas etapas de comum importância: 1) estudo bibliográfico sobre a função social da música para os jovens entre 15 e 17 anos, a importância desta linguagem artística para o desenvolvimento escolar e o uso dos fones de ouvido; 2) indagação, por meio de um questionário específico, a respeito da música e sua função social dirigido aos estudantes desta faixa etária. 


\section{A música ajuda na socialização dos jovens e adolescentes?}

Há inúmeros estudos sobre música e juventude e/ou adolescência ${ }^{1}$. Entender como a música influencia essa faixa etária é objeto de investigação de várias áreas do conhecimento. Arroyo (2007, p. 15), afirma que: "A interação juventude e música popular tem sido foco de interesse de diversas áreas tais como psicologia social da música, estudos de música popular, história cultural, sociologia da música, entre outros". Isso desde os anos 1950, período no qual a indústria cultural iniciou sua rápida expansão.

Segundo Passerini (1996) os adolescentes da década de 1950, a fim de encontrarem novas identidades sociais, diferentes das que estavam sendo formadas nessa época, assumem variados modos de pensar. "Assim, surgiram 'tribos', grupos de jovens que se unem com algum interesse em comum, com múltiplas características” (PEREIRA, 2010, p. 35). Uma dessas tribos, e talvez a mais forte, foi a do rock-and-roll. Segundo a autora, este gênero musical "[...] surgiu fortalecendo vínculos sociais entre os jovens, por meio dele os jovens poderiam partilhar afinidades e identificar-se socialmente. A música com sua função de socializar fez com que o rock-and-roll se tornasse uma manifestação juvenil e cultural” (PEREIRA, 2010, p. 37).

Segundo o survey realizado por Pereira (2010), o rock-and-roll, como gênero musical, não é, na maioria das vezes, preferência entre os adultos: "um dos adolescentes declarou que gosta de escutar música com os amigos: '[...], pois gostamos de rock e nossos pais não gostam' [...]” (PEREIRA, 2010, p. 39). Percebemos, com isso, que as preferências musicais variam muito de geração para geração.

No que diz respeito à relação dos jovens com o meio, Grinspun (2007, p. 36) afirma que: "A noção de pertencimento é fundamental na maturação do jovem. As amizades são relações mais igualitárias que as estabelecidas com os pais e envolvem escolhas e comprometimentos". Do mesmo modo, "as preferências musicais dos adolescentes estariam ligadas a gêneros musicais que para eles possuem um significado relacionado à liberdade de expressão e de mudança" (SOUZA, 2004, p. 8). Isso ainda acontece com o gênero musical citado, o rock-an-roll.

Com isso, podemos afirmar que essas atividades musicais exercidas por essa faixa etária possuem funções sociais. Hummes (2004) estabelece uma lista com as funções da música na sociedade:

Função de expressão emocional; Função do prazer estético; Função de divertimento, entretenimento; Função de comunicação; Função de representação simbólica; Função de validação das instituiçães sociais e dos rituais religiosos; Função de reação física; Função de impor conformidade às normas sociais; Função de contribuição para a continuidade e estabilidade da cultura; e Função de contribuição para a integração da sociedade. (HUMMES, 2004, p. 40).

Esta lista deve ser usada com prudência, pois, além destas podem haver outras funções sociais da música para a juventude, além do fato de que estas funções não podem ser consideradas fixas e aplicáveis a todas as sociedades.

Santos (2006) destaca que a música tem sido evidenciada como um meio, amplo, complexo e, também, diverso, de gerar processos de reconhecimento e diferenciação entre os jovens, "desde os beats, os mods, os skinheads, os punks, os rappers, os clubbers, os roqueiros, os pagodeiros, entre os outros estilos" (SANTOS, 2006, p. 34).

1 Cabe ressaltar que, no Brasil há um uso concomitante dos dois termos: adolescência e juventude, os quais não são sinônimos. "Para a Organização Mundial de Saúde (OMS), a adolescência constituiria um processo fundamentalmente biológico, durante o qual se aceleraria o desenvolvimento cognitivo e a estruturação da personalidade. Abrangeria as idades de 10 a 19 anos, divididas nas etapas de pré-adolescência (dos 10 aos 14 anos) e de adolescência propriamente dita (de 15 a 19 anos). Já o conceito juventude resumiria uma categoria essencialmente sociológica, que indicaria o processo de preparação para os indivíduos assumirem o papel de adulto na sociedade, tanto no plano familiar quanto no profissional, estendendo-se dos 15 aos 24 anos" (OMS/OPS, 1985; SILVA; LOPES, 2009, p. 88). 
Isso acontece devido à música estar incluída no conjunto de códigos que caracterizam os círculos de amizade dessa faixa etária. Ilari (2007) corrobora com essa ideia, ao declarar que a música "[...] serve como uma espécie de distintivo que o adolescente carrega para criar ou fomentar determinada imagem de si e apresentá-la aos outros, para parecer legal e ser aceito em um grupo específico" (ILARI, 2007, p. 74).

Podemos afirmar que, assim como sugere Grinspun (2007), ao dizer que as relações estabelecidas entre os jovens são mais igualitárias que as estabelecidas com os pais, a música tem esse papel de aproximação e, até mesmo, unificação de grupos específicos. E esses precisam ter significados relacionados à liberdade de expressão. A arte é uma forma de expressão e a música é a que mais tem feito parte desse grupo social: jovens e adolescentes.

Sobre aspectos representativos da juventude, Souza e Paiva (2012, p. 353-354) reiteram que: "Não existe uma concepção social única que caracterize e delimite o grupo geracional no qual os jovens estão inseridos, visto que se trata de uma categoria em permanente construção social e histórica". Com isso, Aquino (2009) coloca que mesmo tendo-se um delineamento desse grupo (juventude) que passa por diferentes variações de acordo com contextos particulares, estipula-se a instauração de ciclos de idade, que são definidos a começar pelas condições relacionadas à obtenção da autonomia, colocação no mercado de trabalho, expectativa de vida da população, entre outros.

Portanto, "a juventude não consiste em um fenômeno meramente demográfico. Trata-se de uma complexa condição social, que influencia e é influenciada pelas diferentes culturas e possui uma condição dinâmica e mutável ao longo do tempo [...]" (QUIROGA, 2005 apud SOUZA; PAIVA, 2012, p. 354), levando-se em consideração as transformações da sociedade. Percebemos, com isso, que existem diversos aspectos que influenciam esse grupo social e, consequentemente, sua relação com a música.

\section{Qual a importância da música para o desenvolvimento escolar?}

De acordo com Fonterrada (2008), na Grécia, era atribuído grande valor à música, pois "acreditava-se que ela colaborava na formação do caráter e da cidadania. O valor era extramusical, isto é, seu exercício contribuía para o desenvolvimento ético e a integração do jovem na sociedade" (FONTERRADA, 2008, p. 27). Para Platão e a filosofia grega de modo geral, "a música ocupa uma posição de liderança em relação às outras artes" e "deve-se preservá-la como tarefa do Estado" (FONTERRADA, 2008, p. 27). E, segundo a concepção helênica, "a boa música promove o bem-estar e determina as normas de conduta moral, enquanto a música de baixa qualidade a destrói” (FONTERRADA, 2008, p. 27).

Na década de 1980, o cientista norte-americano Howard Gardner, causou forte impacto na área educacional com sua teoria das inteligências múltiplas. Citado por Lakomy (2014), dentre as oito inteligências estudas, Gardner propôs a musical: "É a competência de pensar em termos musicais, reconhecer tons e sons musicais, observar como podem ser transformados e produzir criativamente música" (LAKOMY, 2014, p. 57). Zagonel (2012, p. 16) esclarece que: "a inteligência musical é a capacidade específica que se manifesta naturalmente no indivíduo, mas que pode ser desenvolvida por meio da prática e dos estudos musicais".

Quando estimulamos a inteligência do estudante, particularmente na infância, estamos colaborando com a sua completa expansão. Isso significa dizer que: "A inteligência musical, com sua própria trajetória de desenvolvimento e representação neurológica, acaba por participar do desenvolvimento da inteligência geral" (ZAMPRONHA, 2007, p. 155).

O desenvolvimento musical, segundo Ilari (2009), pode ser compreendido como um processo biopsicossocial no qual o envolvimento de bebês, crianças e adolescentes com a música podem acontecer por meio dessas três situações: 1) na vida cotidiana, tendo em vista a exposição aos sons 
e às músicas da cultura que o circundam; 2) a partir do aprendizado musical recebido em aulas específicas de música; e 3) aprimorando habilidades em atividades específicas que compõem a área da música, tanto quanto à estética de algum gênero específico ou a cultura em particular. Sendo assim, o engajamento de crianças, adolescentes e adultos com o fazer musical - em casa, na escola, em aulas de instrumento ou em grupos de cultura popular, por exemplo - possibilita o desenvolvimento musical de diversas formas.

A música "não é simplesmente algo que é ouvido e consumido, é algo que é feito na interação com os outros [...]" funcionando "como uma estrutura social e de ação intencional [...]" (CROSS, 2008 apud ILARI, 2009, p. 125), cumprindo uma variedade enorme de funções sociais, além de possibilitar a conexão com outras áreas, como a matemática, literatura, as habilidades espaciais e verbais, as demais linguagens etc.

Zampronha (2007) apoia essa temática quando faz um paralelo da música com a psicologia, psiquiatria e musicoterapia:

A música é um poderoso agente de estimulação motora, sensorial, emocional e intelectual, informa a psicologia. [...] A música tem o poder de evocar, associar e integrar experiências, diz a psiquiatria. [...] Ela é uma atividade temporal, perceptiva, de criação, recriação e/ ou escuta que nunca é passiva, ensina a musicoterapia. [...] A música se relaciona sempre com o indivíduo, pois nasce de sua mente, fala de suas emoções e de sua gama perceptual. (ZAMPRONHA, 2007, p. 17).

A música se comunica com o ser humano por meio de sua estrutura, e uma das principais razões pelas quais engaja tanto o ouvinte é que ela tem o poder de expressar emoções (JUSLIN; LAUKKA, 2004).

A partir da década de 1990, o ensino de Arte passa a ser obrigatório nas escolas brasileiras, "graças, em grande parte, às lutas dos professores de Arte, reunidos em associações e instituições organizadas [...], e a uma insistente reivindicação ao longo do tempo" (ZAGONEL, 2012, p. 19). Portanto, a partir de 1996, mais especificamente, com a promulgação da nova Lei de Diretrizes e Bases da Educação (LDB 9.394/96), o ensino de Arte obtém seu espaço como disciplina obrigatória na educação básica, não sendo mais vista como uma atividade e sim como área do conhecimento.

Pelo ensino de Arte, os alunos podem ter todas as suas capacidades inteligentes estimuladas, "abrangendo uma ampla variedade de domínios, o que nos leva a pensar em uma educação que não privilegie apenas o desenvolvimento do pensamento lógico-matemático, mas o indivíduo no seu todo" (ZAGONEL, 2012, p. 16). As interações com a música, portanto, podem ajudar na formação de relações sociais mais flexíveis e promover capacidades individuais e coletivas.

Girata (2013) expõe que, sobretudo, devido à promulgação da Lei n. ${ }^{\circ} 11.769 / 2008$, que trata da obrigatoriedade do ensino de música na educação básica, o processo de educação musical tem sido tema de muitos debates e discussões nas últimas décadas e revelado grandes desafios. Teóricos da educação e da educação musical têm se debruçado sobre essa questão e desenvolvido estudos significativos relacionados ao ensino de música na escola.

Com isso, Zampronha (2007) cita Basthes (1982) ao indicar que a ferramenta musical liberta na medida em que, não sendo conceitual, possibilita ao educando estruturar valores dentro dos inúmeros expostos e propostos no universo cultural, possibilitando-lhe atribuir significação, ao mesmo tempo em que estabelece um sentido para a sua existência.

Só o exercício da música concretiza os sentimentos de maneira global, abrangente, apresentando aspectos e maneiras de nos sentirmos no mundo (DUARTE JR., 1981 apud ZAMPRONHA, 2007). Desse modo, tendo em conta que o mundo não é só o que pensamos, mas também o que sentimos, infere-se que o que sentimos habita aquela região particularmente humana, quase sempre só acessível à arte, à música. Por isso, devemos oferecer aos estudantes "condições de conhecimento, vivência e desenvolvimento musical [...]", estimulando "diferentes modos de construção de sentidos" (DUARTE JR., 1981 apud ZAMPRONHA, 2007, p. 143). 
Girata (2013, p. 210) afirma que: "Como é de conhecimento geral, a escola é um espaço de formação, transmissão de conhecimentos e produção de saberes, cabendo a ela - escola - também incentivar a prática do 'fazer música". O autor ainda cita Gainza (1988) ao explicar que "a música é fundamental na vida das pessoas, pois ela movimenta e mobiliza diferentes saberes e, por isso, contribui para a transformação e o desenvolvimento integral do ser humano" (GAINZA, 1988 apud GIRATA, 2013). Portanto,

\begin{abstract}
A função do educador musical e da instituição de ensino é garantir o acesso à música de um modo geral, o que também significa não confundir as músicas ditas comerciais e de qualidade duvidosa com estilos musicais específicos, como axé, funk, rap, sertanejo, entre outros. Dessa forma, o ensino de música nas escolas passaria a ter um sentido concreto na vida dos alunos, aproximando-se de seu cotidiano. (GIRATA, 2013, p. 211).
\end{abstract}

A linguagem musical possibilita ao ser humano "criar, expressar-se, conhecer e até transformar a realidade" (TAVARES; CIT, 2013, p. 62). Porém, "para se apropriar dessa linguagem é necessário que seus sentidos sejam educados, formados e sensibilizados para que sua percepção sobre o mundo musical seja ampla e ele possa apreciar inúmeras manifestações musicais" (TAVARES; CIT, 2013, p.62) e, assim, poder criar suas próprias músicas.

Com isso, pontuar a música na educação é assinalar a importância e necessidade de sua prática nas escolas, auxiliar o educando a concretizar sentimentos em formas expressivas, favorecer a interpretação de sua posição no mundo, possibilitar a compreensão de suas vivências, conferir sentido e significado à sua condição de indivíduo e cidadão.

Segundo Gorosito e Furlanetto (2018, p. 5) "não se visa a formação de músicos precoces ou profundos conhecedores de música", na educação musical escolar. Segundo as autoras, com o ensino de música, diversos objetivos socioeducativos podem ser atingidos, como: "sensibilização do ouvido, desenvolvimento rítmico, socialização, expressão corporal, autodisciplina, ampliação do vocabulário, conhecimento de outras culturas" (GOROSITO; FURLANETTO, 2018, p. 5).

Zampronha (2007, p. 175) esclarece que: "Como o cérebro é espantosamente flexível, uma bem orientada prática da música nas escolas pode funcionar como ferramenta auxiliar na formação de novas sinapses, de novas conexões neuronais". Sendo assim, o seu exercício envolve infinitamente mais que o mero reconhecimento dos sons.

Logo, "o ser humano precisa da música, da arte, e a escola não pode deixar de suprir essa necessidade" (TAVARES; CIT, 2013, p. 59). De acordo com as autoras, essa é a forma mais poética e, talvez a mais coerente, de justificar a importância do ensino de música nas escolas.

\title{
O uso de fones de ouvido
}

A história dos tocadores portáteis é muito antiga. Segundo Franceschi (1984), os primeiros registros de vibrações sonoras começaram a surgir já na metade do século XIX. Muitos aparelhos foram fabricados desde então, como: gramofone, LP (long-play), fita magnética, fita cassete, Walkman, CD (Compact Disc), MP3 (Motion Picture Expert Group-Layner3), MP4 (Motion Picture Expert Group-Layner4), Ipod etc.

A partir do Walkman foi possível criar uma individualidade musical, juntamente com os fones de ouvido. Deste modo, tinha-se uma experiência musical independente do local de escuta, mesmo que estes fossem locais públicos, repleto de pessoas. Com a chegada dos aparelhos digitais e tocadores portáteis a experiência musical individual pode ser realizada em qualquer tempo e local, pois há um fechamento para os sons externos, fazendo com que os sons musicais fiquem sobrepostos a eles e independentes da acústica do local. 
Grande parte das pessoas que "utilizam os tocadores de música constitui um grupo social característico: os adolescentes. Eles estão constantemente em contato com a música, uma vez que boa parte tem atração pelas descobertas no mundo tecnológico" (PEREIRA, 2010, p. 10). E o fone de ouvido, segundo essa autora,"trouxe novas experiências individuais de audição musical além da acessibilidade à música em qualquer local” (PEREIRA, 2010, p. 10).

Observamos, também, que hoje a exigência em relação à qualidade da gravação é muito maior, especialmente por esse público, pois, como afirma Pereira (2010), o maior grupo de ouvintes usando fones de ouvido são os jovens. Não se admite nenhum tipo de ruído nas gravações, uma vez que, ouve-se o som diretamente no ouvido, sem nenhuma influência de sons externos. Não importa se estamos em um ônibus cheio de pessoas ou se estamos sozinhos em um parque. Não importa também se a acústica é boa ou não. O que importa é a qualidade do som que está sendo ouvido diretamente em nossos ouvidos. Por essas e outras razões, os jovens continuam a buscar novas tecnologias. Querem aquilo que está na moda e o que mais os fizerem ser aceitos em um grupo.

Com isso, vemos que ao usar fones de ouvido, os jovens podem ter novas sensações e experiências musicais. Deste modo, o uso dos mesmos proporciona uma experiência mais individual. Ninguém é obrigado a ouvir aquilo que não gosta ou não quer. Isso não acontecia há cerca de 50 anos atrás, salienta Pereira (2010).

\section{Metodologia}

Além do aporte bibliográfico exposto acima, realizou-se uma pesquisa de opinião pública com participantes não identificados ${ }^{2}$, com caráter quantitativo, utilizando como recurso de coleta de dados um questionário contendo onze perguntas referentes ao assunto da pesquisa.

O questionário permite ao participante uma maior liberdade para expressar sua opinião, pois este "[...] é um instrumento de coleta de dados, constituído por uma série ordenada de perguntas, que devem ser respondidas por escrito e sem a presença do entrevistador" (BABBIE, 1999, p. 201). $\mathrm{O}$ fato do pesquisador não estar presente no momento em que são dadas as respostas torna $\mathrm{o}$ participante completamente anônimo, ao contrário da entrevista, que se caracteriza por "[...] uma conversação efetuada face a face" (LAKATOS; MARCONI, 1991, p. 196).

Para não limitar a pesquisa com respostas prontas, o questionário tinha apenas uma pergunta com diferentes opções pré-determinadas e dez perguntas abertas, permitindo ao participante, maior liberdade de resposta. De acordo com Andrade (1998, p. 129), "perguntas fechadas são aquelas que indicam três ou quatro opções de resposta ou se limitam à resposta afirmativa ou negativa, e já trazem espaços destinados à marcação da escolha".

Para tanto, os questionários foram disponibilizados em uma comunidade religiosa durante uma celebração com ampla participação de jovens, sendo que os únicos critérios estabelecidos foram a faixa etária ${ }^{3}$ ( 15 a 17 anos) e que os mesmos estivessem regularmente matriculados em uma unidade de ensino, permitindo, assim, o anonimato dos participantes.

Desta maneira, no começo da celebração, foi comunicado sobre a pesquisa e aqueles que quiseram voluntariamente participar, puderam retirar a ficha, responder às questões e, ao final da celebração, depositar as mesmas em uma caixa sem qualquer interferência ou identificação. Com isso, participaram da pesquisa vinte jovens entre 15 e 17 anos.

\footnotetext{
2 A pesquisa foi realizada conforme os critérios estabelecidos no Inciso I, do Parágrafo Único, do Artigo 1ㅇ da Resolução $510 / 2016$ do Conselho Nacional de Saúde - CNS

3 A escolha por essa faixa etária se justifica pelo fato de serem oriundos de várias culturas e de distintas situações socioeconômicas. Além disso, a escola é um ambiente essencialmente jovem, já que o Estado assegura o acesso do adolescente à escola, como consta no Artigo 54 do Estatuto da Criança e do Adolescente (BRASIL, 1990).
} 
Para a coleta de dados, foram elencadas as questões pertinentes aos propósitos gerais deste trabalho, como considera Charlot (2000, p. 9): "Não basta, porém, coletar dados; deve-se também saber exatamente o que se procura. E isso é ainda mais necessário quando se aborda uma questão antiga de uma forma relativamente nova". Além da importância de estar centrado no objeto de estudo durante a elaboração do questionário, Babbie (1999, p. 313) ressalta que: "As perguntas devem fazer sentido para os respondentes [...]. Igualmente, as categorias de respostas (se fornecidas) devem fazer sentido, tanto em si mesmas quanto na relação com a pergunta, e umas com as outras".

Desta forma, o questionário utilizado nesta pesquisa conteve perguntas sobre os modos, gostos e hábitos de escuta musical dos jovens, a utilização de fones de ouvido e sobre a função socializadora da música. Foi investigado também se o uso de fones de ouvido pode influenciar ou distrair os estudantes, comprometendo seu desenvolvimento escolar na ótica dos mesmos. Assim, o questionário foi dividido em três sessões:

1. Modos de ouvir música e gostos musicais: questões 1 a 4 .

2. Função social da música e relação do participante com a mesma: questões 5 a 9.

3. Sobre o uso de fones de ouvido e a influência no rendimento escolar: questões 10 e 11.

Com isso, as perguntas expostas no questionário foram as seguintes: 1) Assinale em quais momentos e lugares você ouve música. 2) Você costuma ouvir música com amigos, familiares ou colegas? Em quais momentos? 3) Você ouve música sozinho? Em quais situações? 4) Você ouve quais estilos e gêneros musicais? 5) Você acha que a música ajuda na socialização? Por quê? 6) Você acha que a música pode nos distanciar das pessoas? Por quê? 7) Você participa de algum grupo musical? Se sim, qual? 8) Você costuma participar de alguma roda de música? Se sim, qual o tipo de repertório (quais músicas são tocadas)? 9) Você já teve ou tem contato com a música através de algum instrumento musical? 10) Você costuma ouvir música utilizando fones de ouvido? Com que frequência? Em quais momentos e lugares? 11) Você acha que o uso de fones de ouvido pode influenciar ou distrair os estudantes, comprometendo seu desenvolvimento escolar?

A seguir, serão expostos os gráficos referentes aos resultados da pesquisa realizada que corroboram com a revisão de literatura apresentada sobre a temática em questão. 


\section{Resultados}

No primeiro Gráfico, podemos observar que todos os participantes assinalaram as opções "casa e quarto" ao serem questionados sobre os espaços onde costumam ouvir música. E destes, apenas $40 \%$ afirmaram escutar música na unidade de ensino (colégio), o que nos leva a ponderar que mais da metade dos estudantes não tem relação com a música em um ambiente educacional. Percebemos, com isso, que a música na escola ainda é pouco vivenciada, desfavorecendo, assim, o desenvolvimento global deste indivíduo.

\section{Gráfico 1 - Espaços onde os jovens escutam música}

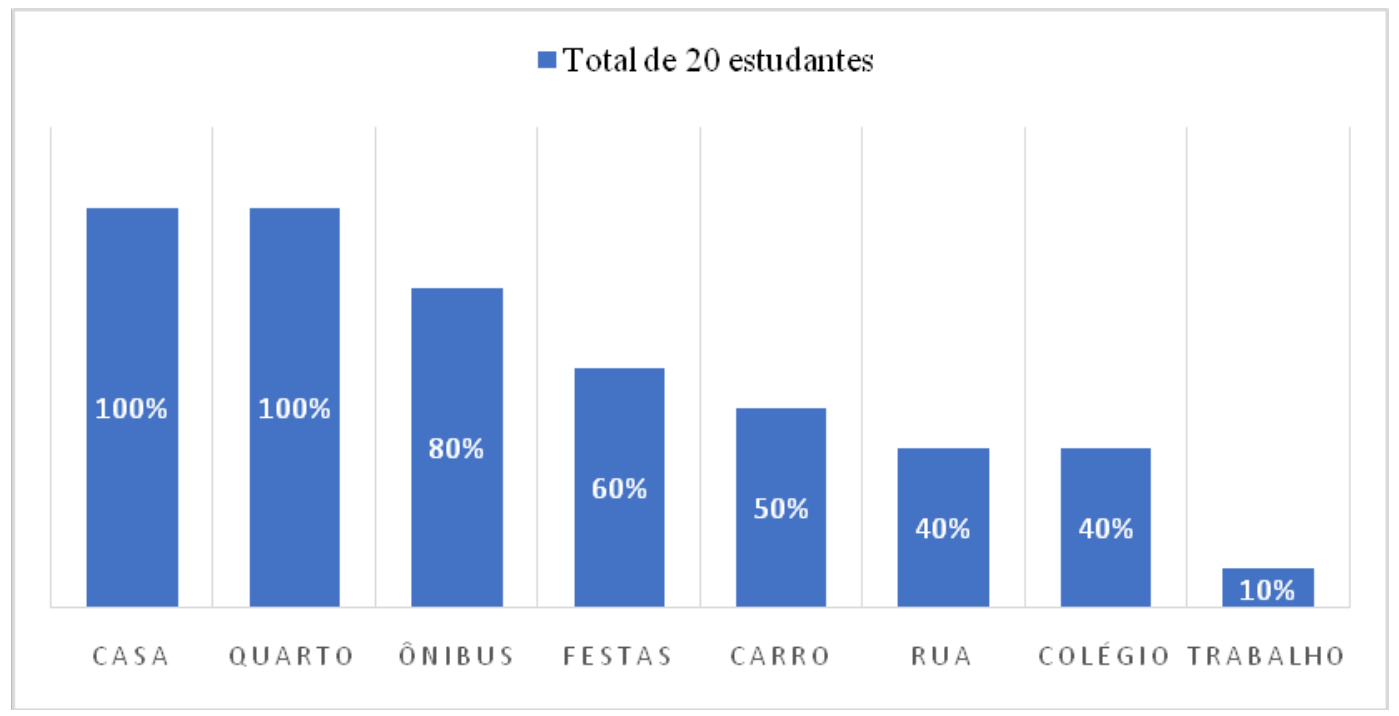

Fonte: Elaborado pela autora.

Já no segundo Gráfico, sobre os gostos e preferências musicais dos jovens, percebemos que não houve nenhuma resposta com relação à música erudita ou contemporânea.

Zagonel (2012, p. 18), ao citar Porcher (1982), expõe que as pessoas não familiarizadas com a arte têm uma certa inclinação "à cegueira ou à surdez estética". Com isso, não podemos esperar que o aluno que nunca teve contato com a música contemporânea ou erudita, por exemplo, venha compreendê-la ou apreciá-la.

Para tanto, percebemos, mais uma vez, o quanto é imprescindível a inserção da música no ambiente educacional, uma vez que, o objeto de estudo da música na escola envolve toda produção musical na sua diversidade cultural em diferentes tempos e espaços ${ }^{4}$, ou seja, abrangendo os diferentes estilos e gêneros (música erudita, popular, étnica, midiática, folclórica etc.), promovendo, assim, a ampliação de repertório e o desenvolvimento do pensamento artístico e estético musical.

De acordo com a Base Nacional Comum Curricular (BNCC), promulgada em 2017, o ensino de Arte deve contemplar as quatro linguagens artísticas: música, dança, teatro e artes visuais. Sendo que as mesmas:

[...] articulam saberes referentes a produtos e fenômenos artísticos e envolvem as práticas de criar, ler, produzir, construir, exteriorizar e refletir sobre formas artísticas. A sensibilidade, a intuição, o pensamento, as emoções e as subjetividades se manifestam como formas de expressão no processo de aprendizagem em Arte. (BRASIL, 2017, p. 193).

4 Segundo a BNCC, "os conhecimentos, processos e técnicas produzidos e acumulados ao longo do tempo" em cada uma das linguagens artísticas "possibilitam compreender as relações entre tempos e contextos sociais dos sujeitos na sua interação com a arte e a cultura”. Além de contribuir para "a contextualização dos saberes e das práticas artísticas" (BRASIL, 2017, p. 193). 
Portanto, é evidente que o ser humano precisa de todas essas vivências artísticas para o seu completo desenvolvimento e é dever da escola proporcionar as experiências e os saberes correspondentes a cada área do conhecimento.

\section{Gráfico 2 - Estilos e/ou gêneros musicais}

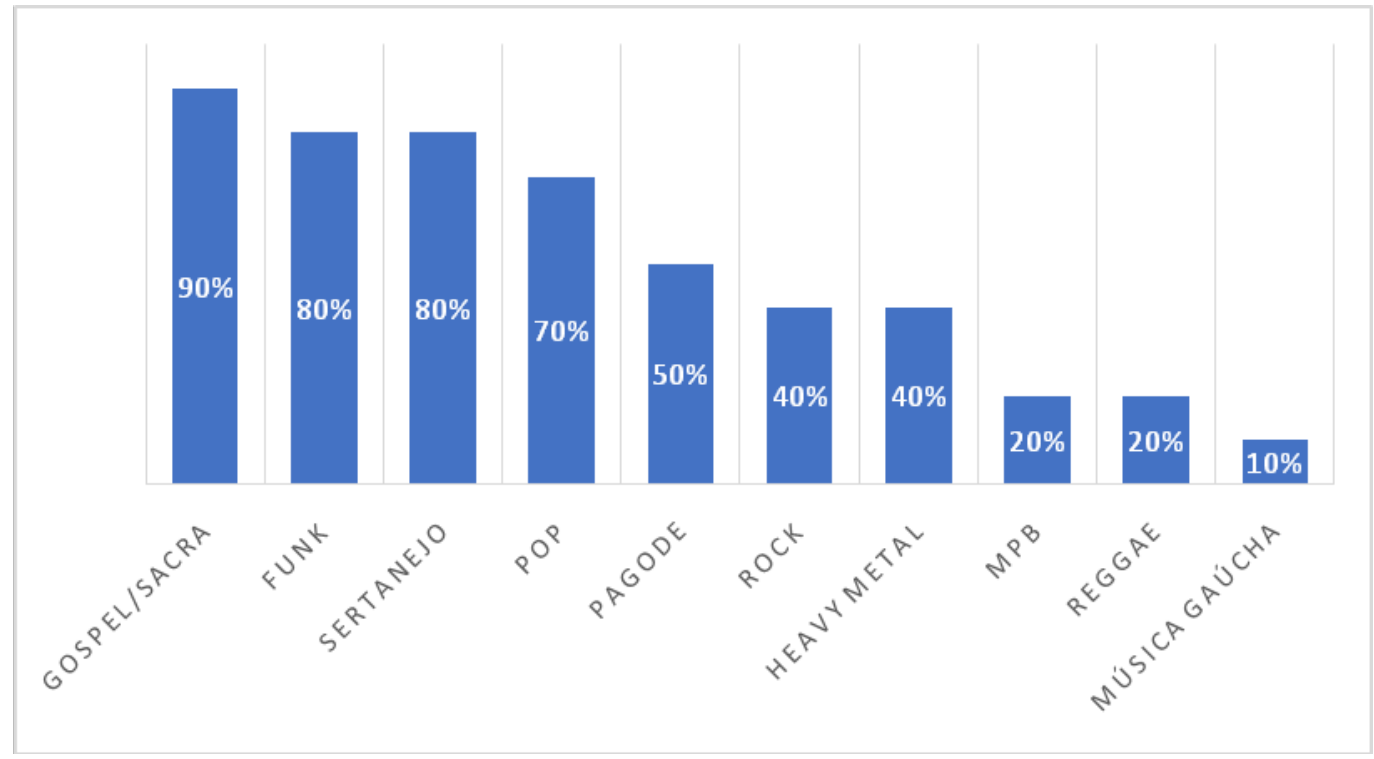

Fonte: Elaborado pela autora.

Seguindo os resultados obtidos pelo questionário, no terceiro Gráfico, podemos notar que $70 \%$ dos participantes afirmaram que a música ajuda na socialização e $30 \%$ dos participantes afirmaram que não ajuda.

Destacamos aqui que, esse último percentual corresponde aos mesmos participantes que afirmaram usar fones de ouvido em quase todas as vezes que escutam música e que não participam de grupos musicais, ou seja, a interação coletiva é quase nula, impedindo, deste modo, a socialização através da música.

\section{Gráfico 3 - Socialização da música}

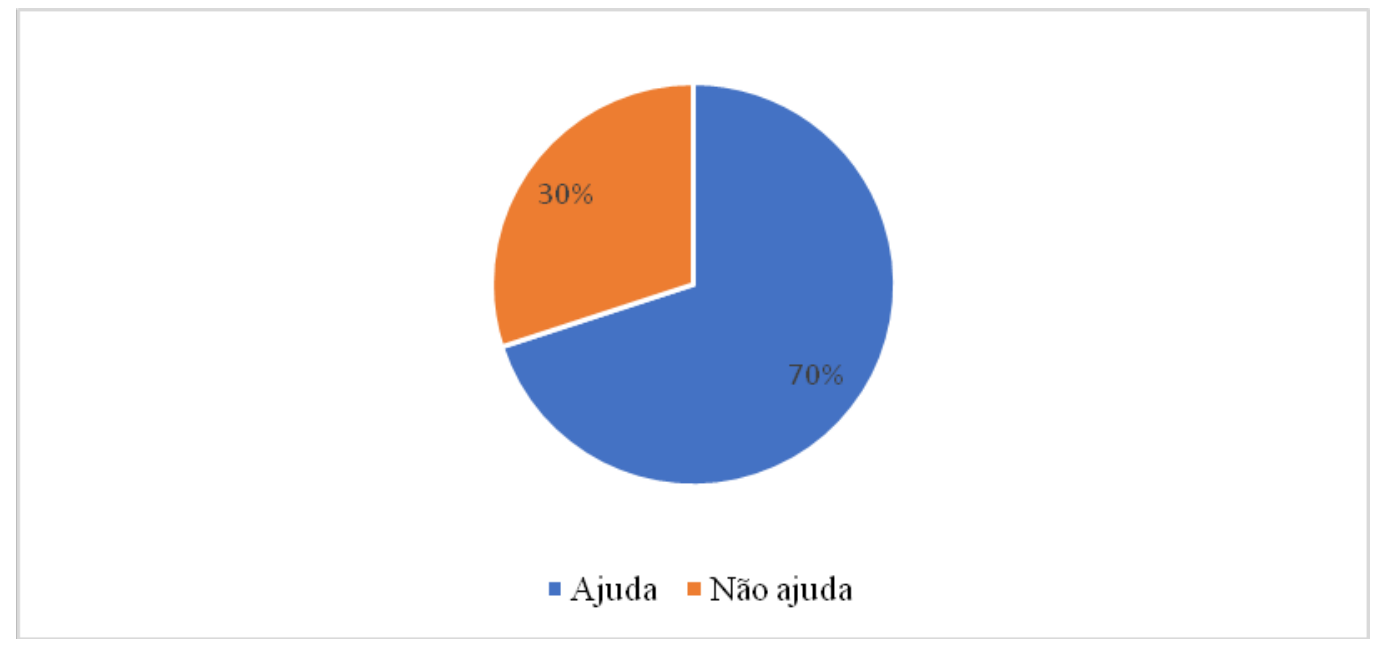

Fonte: Elaborado pela autora.

Já no quarto Gráfico, sobre a participação/execução musical, 50\% dos participantes assinalaram que tocam algum instrumento musical e desses, 30\% participam de algum grupo de música. 
Com isso, percebemos que, há um número considerável dos participantes engajados com o fazer musical através de aulas de instrumento e participação em grupos musicais, o que colabora com o seu desenvolvimento global, conforme exposto anteriormente.

\section{Gráfico 4 - Participação/execução musical}

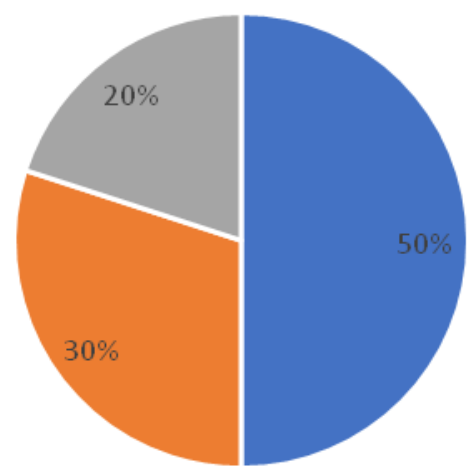

- Toca algum instrumento = Participa de grupo musical $=$ Não tocam e nem participam

Fonte: Elaborado pela autora.

Para quantificar a utilização de fones de ouvido pelos participantes, no quinto Gráfico, temos um comparativo entre o nível de frequência desse uso.

Mesmo a juventude sendo o grupo que mais utiliza fones de ouvido, percebemos que a maioria dos participantes (60\%) sinalizaram que esse uso é pouco frequente. Podemos dizer com base nas respostas fornecidas pelo grupo pesquisado, que os ambientes nos quais os mesmos mais utilizam esse acessório são: quarto, ônibus, carro e rua.

\section{Gráfico 5 - Uso de fones de ouvido}

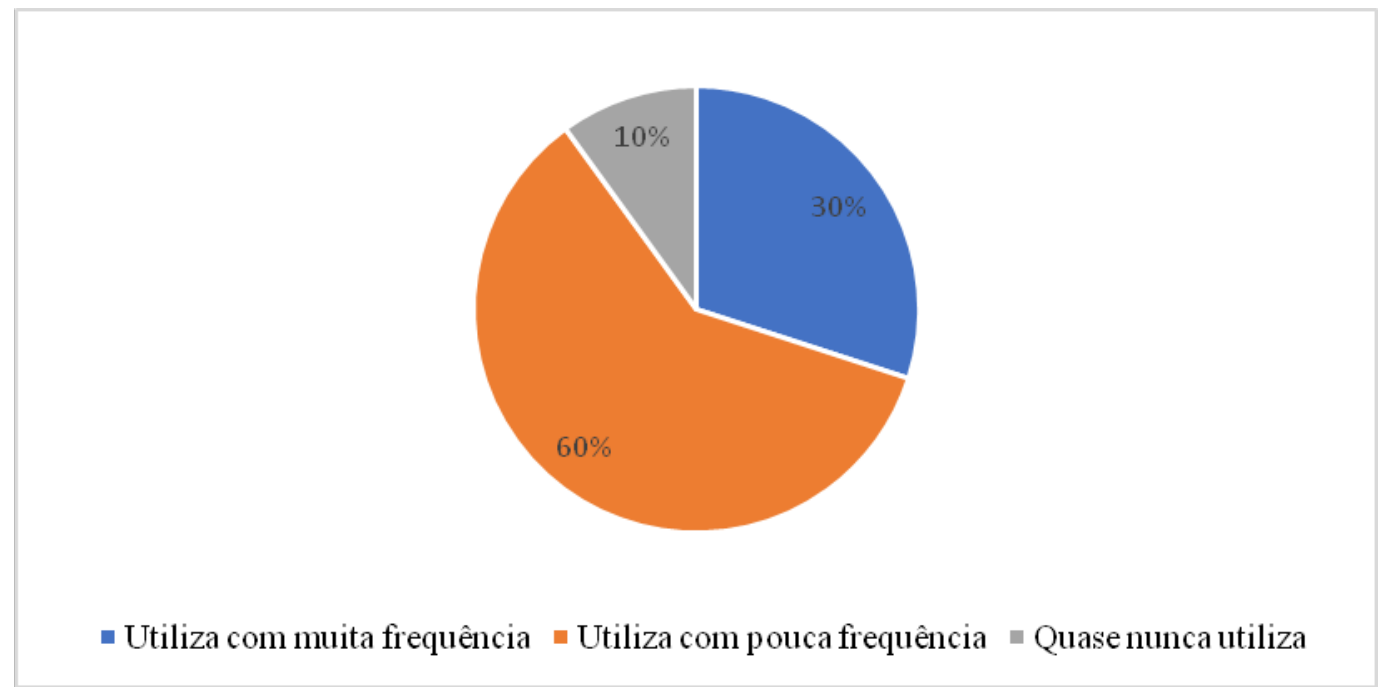

Fonte: Elaborado pela autora.

Por fim, no sexto Gráfico, temos o resultado sobre a utilização dos fones de ouvido ser fator de distração ou não para os estudantes, prejudicando, assim, seu rendimento escolar, sendo que $70 \%$ dos participantes responderam que sim e $30 \%$ responderam que não. 
Entre os que afirmaram que sim, justificaram sua resposta dizendo que: "Mesmo sendo proibido o uso de celular e de fones de ouvido na sala de aula, sempre tem aqueles que desrespeitam essa regra e acabam utilizando e isso descontextualiza o aluno do momento da aprendizagem"; "Afeta a audição quando usado de forma incorreta"; "Dispersa com muita facilidade e te deixa perdido com relação à explicação do professor"; "Faz com que você perca momentos de conversa com os amigos ou sua família"; "Se usar demais e com volume intenso, a gente sente um zumbido no ouvido e acaba tendo que aumentar o volume de tudo, até da nossa voz [...], e o professor precisa falar mais alto pra gente entender"; "Se você estiver usando na rua, pode se distrair e não ouvir a buzina de um carro e pode ser até atropelado"; "Tem gente que gosta de estudar ouvindo música com fones de ouvido, mas eu acho que me atrapalha, fico perdido e tenho que ler tudo de novo"; entre outros.

Entre os que afirmaram que não, as justificativas foram: "Não me sinto distraído e tenho bom rendimento escolar"; "Não é permitido usar fones de ouvido na sala de aula"; "Só uso fones de ouvido no intervalo e na rua"; "Não atrapalha, porque eu não levo para a escola, é proibido"; etc.

\section{Gráfico 6 - Sobre os fones de ouvido distraírem ou não os estudantes, comprometendo seu desenvolvimento escolar}

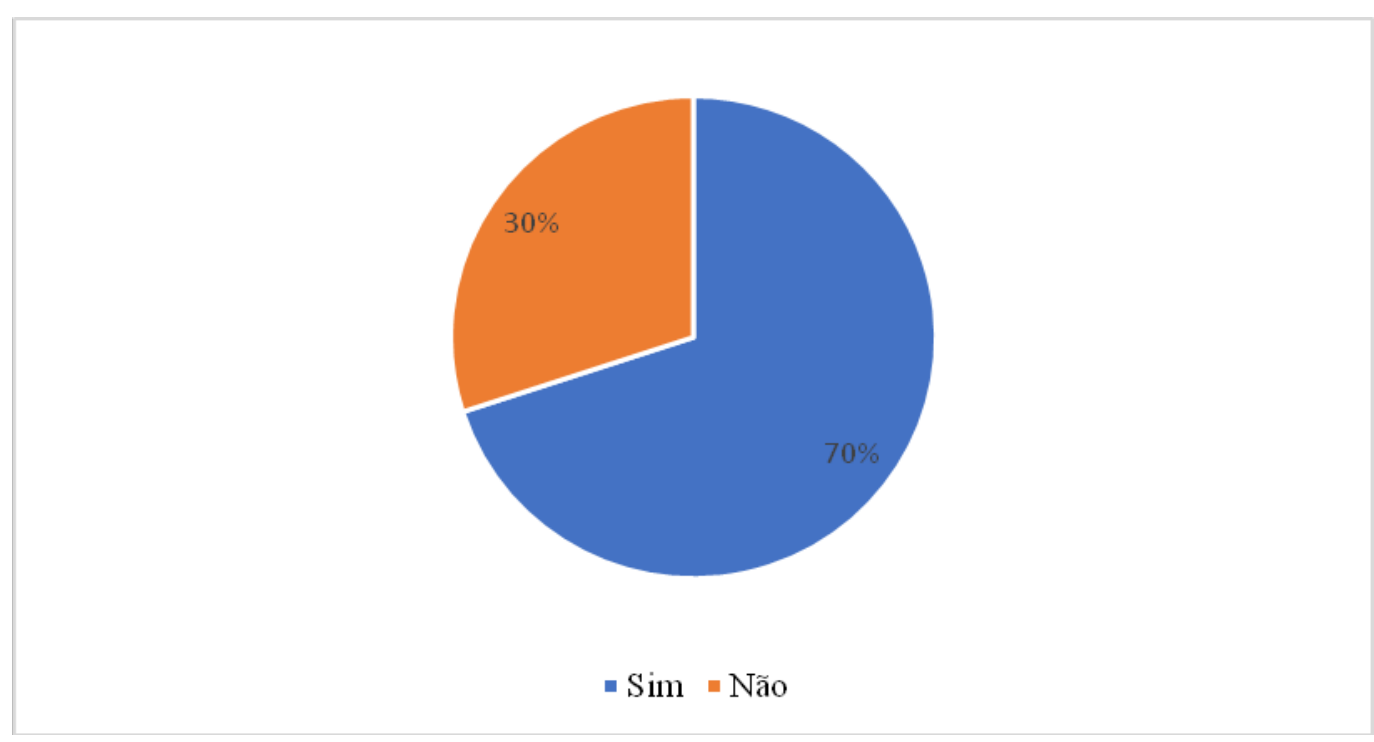

Fonte: Elaborado pela autora.

\section{Considerações finais}

Ao longo desse discurso sobre a influência da música no desenvolvimento escolar e a utilização de fones de ouvido entre os jovens de 15 a 17 anos, percebemos que os resultados obtidos, por meio dos referenciais bibliográficos, indicam que os jovens têm a necessidade de criar uma imagem para apresentá-la aos outros e a música está intimamente ligada a esses processos de expressão, liberdade e aceitação em um determinado grupo. Esses resultados também aparecem no questionário aplicado aos jovens da faixa etária em questão, uma vez que os mesmos afirmaram ouvir determinados gêneros e estilos musicais para não se sentirem excluídos. Com isso, percebemos que a música está incluída no conjunto de códigos que caracterizam os círculos de amizade dessa faixa etária.

Podemos dizer, portanto, que a música tem papel socializador quando é feita, ouvida e refletida por um grupo, ou seja, de forma coletiva e que o uso constante de fones de ouvido, atrapalha o desenvolvimento dos estudantes quando os privam de situações coletivas. Em contrapartida, percebemos que a música tem papel fundamental na escola, pois a mesma proporciona momentos de interação, socialização e coletividade. 
Considerando que a música aproxima, estabelece conexões e interações, promovendo inúmeros benefícios e que, especialmente para os jovens, possui função social de pertencimento e liberdade de expressão com elevada importância, é natural que ela - a música - tenha papel significativo no desenvolvimento social e educacional dos mesmos.

Simultaneamente, a utilização de fones de ouvido faz parte desse grupo trazendo novas experiências de audição musical, que sim, são individualizadas, porém permitem acesso à música em qualquer ambiente. Por esses e outros motivos, devem ser utilizados com cautela para não prejudicar a socialização, interação e o rendimento escolar desses jovens.

Portanto, conclui-se com essa pesquisa que, apesar de a literatura trazer reflexões importantes, esse estudo precisa de mais trabalho de campo, considerando de suma importância a análise de outros estudantes, a fim de entender como a música influencia seu desenvolvimento social e educacional e qual a função do uso de fones de ouvido, proporcionando, assim, novas contribuições acerca do tema proposto.

\section{Referências}

ANDRADE, Maria Margarida de. Introdução à metodologia do trabalho científico. 3. ed. São Paulo: Atlas, 1998.

AQUINO, Luseni. A juventude como foco das políticas públicas. In: CASTRO, Jorge Abrahão de; AQUINO, Luseni Maria Cordeiro de; ANDRADE, Carla Coelho de (org.). Juventude e Políticas Sociais no Brasil. Brasília, DF: IPEA, 2009. p. 25-39. Disponível em: https://www.ipea.gov.br/portal/images/stories/PDFs/livros/livro_juventudepolitica. pdf. Acesso em: 31 jan. 2021.

ARROYO, Margarete. Escola, juventude e música: tensões, possibilidades e paradoxos. Em Pauta, Porto Alegre, v. 18, n. 30, p. 5-39, jan./jun. 2007.

BABBIE, Earl. Métodos de pesquisas de Survey. Belo Horizonte: Editora UFMG, 1999.

BRASIL. Ministério da Educação. Base Nacional Comum Curricular (BNCC): Educação é a Base. Brasília, DF: MEC/ CONSED/UNDIME, 2017. Disponível em: http://basenacionalcomum.mec.gov.br/images/BNCC_EI_EF_110518_versaofinal_site.pdf. Acesso em: 31 jan. 2021.

BRASIL. Lei no 8.069, de 13 de julho de 1990. Dispõe sobre o Estatuto da Criança e do Adolescente e dá outras providências. Brasília, DF: Presidência da República, 1990. Disponível em: https://crianca.mppr.mp.br/arquivos/File/publi/ camara/estatuto_crianca_adolescente_9ed.pdf. Acesso em: 20 jan. 2021.

BRASIL. Ministério da Saúde. Conselho Nacional de Saúde. Resolução no 510, de 7 de abril de 2016. Trata sobre as diretrizes e normas regulamentadoras de pesquisa em ciências humanas e sociais. Diário Oficial da União, Brasília, DF, 2016. Disponível em: http://conselho.saude.gov.br/resolucoes/2016/Reso510.pdf. Acesso em: 31 jan. 2021.

CHARLOT, Bernard. Da relação com o saber: elementos para uma teoria. Porto Alegre: Artes Médicas Sul, 2000.

FONTERRADA, Maria Trench de Oliveira. De tramas e fios: um ensaio sobre música e educação. 2. ed. São Paulo: Editora UNESP; Rio de Janeiro: Funarte, 2008.

FRANCESCHI, Humberto Moraes. Registro sonoro por meios mecânicos no Brasil. Rio de janeiro: Studio HMF, 1984. GIL, Antônio Carlos. Métodos e técnicas de pesquisa social. 5. ed. São Paulo: Atlas, 1999.

GIRATA, Paulo Youtaka Toyoshima. Oficina de violão: uma experiência de ensino e aprendizagem com alunos da educação básica. In: SIMPÓSIO ACADÊMICO DE VIOLÃO DA EMBAP, 7., 2013, Curitiba. Anais [...]. Curitiba: EMBAP, 2013. p. 208.

GOROSITO, Haydée Seeling; FURLANETTO, Beatriz Helena. Tixa Tixa: Uma lagartixa no mundo musical. 2. ed. Curitiba: Letra \& Saber, 2018.

GRINSPUN, Mírian Paura Sabrosa Zippin. A razão dos afetos. Revista O olhar adolescente, São Paulo, v. 4, p. 30-37, nov. 2007. 
HUMMES, Júlia Maria. Por que é importante o ensino de música? Considerações sobre as funções da música na sociedade e na escola. Revista da ABEM, Porto Alegre, v. 12, n. 11, p. 17-25, set. 2004.

ILARI, Beatriz. Em sintonia com o mundo. O olhar adolescente: os incríveis anos de transição para a idade adulta. Caminhos da Cognição. Especial Mente e Cérebro, São Paulo, n. 3, p. 72-79, nov. 2007.

ILARI, Beatriz. Música na infância e na adolescência: um livro para pais, professores e aficionados. Curitiba: Ibpex, 2009.

JUSLIN, Patrik. N.; LAUKKA, Petri. Expression, Perception, and Induction of Musical Emotions: A Review and a Questionnaire Study of Everyday Listening. Journal of New Music Research, Reino Unido, v. 33, n. 3, p. 217-238, 2004.

LAKATOS, Eva Maria; MARCONI, Marina de Andrade. Fundamentos de metodologia científica. 3. ed. São Paulo: Atlas, 1991.

LAKOMY, Ana Maria. Teorias cognitivas da aprendizagem. Curitiba: InterSaberes, 2014.

PASSERINI, Luisa. A juventude, metáfora da mudança social. Dois debates sobre os jovens: A Itália fascista e os Estados Unidos na década de 1950. In: LEVI, Giovanni; SCHMITT, Jean-Claude (org.). História dos jovens: A época contemporânea. São Paulo: Companhia das Letras, 1996. v. 2. p. 319-382.

PEREIRA, Priscila. A utilização de tocadores portáteis de música e sua consequência para a escuta musical de adolescentes. 2010. Dissertação (Mestrado em Música) - Setor de Ciências Humanas, Letras e Artes, Universidade Federal do Paraná, Curitiba, 2010.

SANTOS, Lisiane Gazola. Sons das tribos: compondo identidades juvenis em uma escola urbana de Porto Alegre. 2006. Dissertação (Mestrado em Educação) - Programa de Pós-Graduação em Educação, Universidade Federal do Rio Grande do Sul, Porto Alegre, 2006.

SILVA, Carla Regina; LOPES, Roseli Esquerdo. Adolescência e juventude: entre conceitos e políticas públicas. Cadernos de Terapia Ocupacional da UFSCar, São Carlos, v. 17, n. 2, p. 87-106, jul./dez. 2009. Disponível em: http://www.cadernosdeterapiaocupacional.ufscar.br/index.php/cadernos/article/viewFile/100/65. Acesso em: 31 jan. 2021.

SOUZA, Jussamara. Educação musical e práticas sociais. Revista da ABEM, Porto Alegre, v. 12, n. 10, p. 7-11, mar. 2004.

SOUZA, Candida de; PAIVA, Ilana Lemos de. Faces da juventude brasileira: entre o ideal e o real. Estudos de psicologia, Natal, v. 17, n. 3, p. 353-360, set./dez. 2012. Disponível em: https://www.scielo.br/pdf/epsic/v17n3/02.pdf. Acesso em: 31 jan. 2021.

TAVARES, Isis Moura; CIT, Simone. Linguagem da Música. Curitiba: InterSaberes, 2013.

ZAGONEL, Bernadete. Arte na educação escolar. Curitiba: InterSaberes, 2012.

ZAMPRONHA, Maria de Lourdes Sekeff. Da música, seus usos e recursos. 2. ed. rev. e ampliada. São Paulo: Editora UNESP, 2007.

Data de submissão: 26/01/2021

Data de aceite: 05/02/2021 